\title{
Novel Synergistic Activity of Quercus infectoria Gall Extract with Ceftazidime Against Standard and Multiple Drug Resistant Pseudomonas aeruginosa and Escherichia coli Isolates
}

\author{
Elham Isaei, MD"; Shahla Mansouri, PhD ${ }^{2,3^{*}}$; Maryam Rahmani, MD4; Fariba Sharififar, PhD ${ }^{5}$; Atefeh Salary, MD ${ }^{1}$ \\ 'Student Research Committee, Kerman University of Medical Sciences, Kerman, Iran \\ ${ }^{2}$ Medical Mycology and Bacteriology Research Center, Kerman University of Medical Sciences, Kerman, Iran \\ ${ }^{3}$ Department of Medical Microbiology (Bacteriology \& Virology), Afzalipour Faculty of Medicine, Kerman University of Medical \\ Sciences, Kerman, Iran \\ ${ }^{4}$ Research Center of Tropical and Infectious Diseases, Kerman University of Medical Sciences, Kerman, Iran \\ ${ }^{5} \mathrm{Herbal}$ and Traditional Medicines Research Center, Kerman University of Medical Sciences, Kerman, Iran
}

\begin{abstract}
Background: Multidrug resistance pathogens are important heath challenges. In this study, the antibacterial activity of 20 plant extracts was tested against standard as well as 20 multidrug-resistant (MDR) strains of Pseudomonas aeruginosa and Escherichia coli. The most active plant extract (Quercus infectoria) was selected for the synergistic activity assay.

Methods: Plant extracts were prepared by maceration using water, methanol and ethanol. The antibacterial activity of extracts was determined by both broth and agar dilution methods. The synergistic activity of QIG with ceftazidime (CAZ) was evaluated by checker board assay. Antioxidant activity was determined by colorimetric Ferric reducing antioxidant power (FRAP) assay. Results: Only the methanol extract of QIG inhibited the growth of all the bacterial strains at a concentration of $1000 \mu \mathrm{g} / \mathrm{mL}$. Other active extracts were Myrtus communis and Eucalyptus globulus inhibiting the growth of most bacterial strains tested at $2000 \mu \mathrm{g} /$ $\mathrm{mL}$. In checker board assay, the minimum inhibitory concentration (MIC) to both QIG extract and CAZ was reduced. The MIC of CAZ was reduced from $64-4096 \mu \mathrm{g} / \mathrm{mL}$ to $4 \mu \mathrm{g} / \mathrm{mL}$ for $P$. aeruginosa and to $16 \mu \mathrm{g} / \mathrm{mL}$ for $E$. coli isolates.

Conclusion: The QIG extract exhibited potent antioxidant activity determined by FRAP assay. The result of this study showed a strong synergistic activity between QIC and CAZ on P. aeruginosa and E. coli. The activity within ethyl acetate-methanol (7:3) fraction indicates that the active components of the plant have a semi-polar nature and further work with this fraction may lead to understanding the mechanism of this synergistic activity.

Keywords: Ceftazidime, Escherichia coli, Pseudomonas, Quercus infectoria

Cite this article as: Isaei E, Mansouri S, Rahmani M, Sharififar F, Salary A. Novel synergistic activity of Quercus infectoria gall extract with ceftazidime against standard and multiple drug resistant Pseudomonas aeruginosa and Escherichia coli isolates. Arch Iran Med. 2021;24(9):684-688. doi: 10.34172/aim.2021.98
\end{abstract}

Received: September 4, 2020, Accepted: April 21, 2021, ePublished: September 1, 2021

\section{Introduction}

Antimicrobial resistance in gram-negative bacteria is a significant cause of infections in the community as well as hospital settings. Rapid emergence of resistance in gram-negative enteric bacteria and non-fermenting gram-negative bacteria such as Klebsiella pneumonia, Escherichia coli and Pseudomonas aeruginosa are reported worldwide. ${ }^{1}$ Presence of these highly resistant strains in the hospitals are important causes of morbidity, mortality and also financial health care costs. ${ }^{2}$ The most important challenge in the treatment of infections with these bacteria, especially $P$. aeruginosa, are intrinsic or acquired resistance to a range of antibacterial agents, resulting in the emergence of multidrug-resistant $(M D R)$, extensively drug-resistant (XDR) or pandrug-resistant (PDR) strains. ${ }^{2,3}$ Recently, the rate of resistance to expanded spectrum $\beta$-lactamases, which are among the most prescribed antimicrobial agents in the hospitals, is steadily increasing. These agents have a broad spectrum of activity against both gram-positive and gram-negative bacteria with a low toxicity profile, which is the reason for their widespread usage. ${ }^{4}$ Resistance to cephalosporin could be due to intrinsic factors such as production of inactivating enzyme, presence of efflux pumps, outer membrane permeability reduction or acquisition of resistance genes from other microorganisms. ${ }^{5}$ Many bacteria are able to form biofilms, and the barrier nature of the biofilm matrix results in lack of immune response and more virulent and difficult to eradicate bacteria which results in emergence of drug resistance and persistent and chronic infections. ${ }^{3}$ Biofilm and antibacterial resistance are reported to be related; for 
example, ceftazidime (CAZ) resistance and production of biofilms in E. coli has been reported. ${ }^{3}$ Combination of two antibacterial agents for difficult to treat infections has been used to reduce the chance of bacterial resistance, and reduce the minimum inhibitory concentration (MIC) for more toxic drugs. ${ }^{4}$ In this respect, the use of an antibacterial agent in conjugation with plant extracts or Nano-particles is recommended by many investigators to overcome the emergence of resistance and to reduce the MIC to more common and relatively safer antibacterial agents. ${ }^{4-7}$ Medicinal plants have long been used to cure various diseases, and many plants with antibacterial, anticancer and active against other clinical diseases are reported. ${ }^{8,9}$ Plant extracts may have other targets than the antibacterial agents and their combination with antibacterial agents may result in a synergistic activity between them. ${ }^{10-12}$ Bacterial infections could cause the release of free radicals which may robustly change cellular metabolism. The antimicrobial activity may therefore be due to the presence of free radical preventive antioxidants in extracts that could inhibit the activity of free radicals and reactive oxygen species, thus contributing to the fight against diseases caused by bacteria and other pathogens. Quercus infectoria Olivier (oak) (Fagaceae family) is an endemic plant in Iran, Greece and different regions of Asia. ${ }^{13}$ In the literature, the plant galls have been reported to have antibacterial, anti-biofilm, inhibition of bacterial virulence factors, antifungal activity, anti-tyrosinase activity, antioxidant activity and cytotoxicity against cervical and ovarian cancer cell lines. ${ }^{14-16}$ In this study, the synergistic activity of methanol and fractionated methanol extracts of QIC which showed the highest antibacterial activity in comparison with other plant extracts was evaluated against MDR and CAZ resistant clinical isolates of $P$. aeruginosa and $E$. coli by checker board assay. The antioxidant activity of this extract and different fractions were also determined in this study.

\section{Materials and Methods \\ Plants Used}

The following plants were collected either from various parts of Iran or were purchased from trusted medicinal herbal markets, and their activity against standard strains of $P$. aeruginosa and E. coli were evaluated.

Aerial parts of Glycyrrhiza glabra (Fabaceae), Sizigium aromaticus (Myrtaceae), Hypericum perforatum (Hypericaceae), Echinacea angustifolia (Asteraceae), Foeniculum vulgare (Apiaceae), Rosmarinus officinalis (Lamiaceae), Urtica dioica (Urticaceae), Zataria multiflora (Lamiaceae); Leaves of Eucalyptus globulus. (Myrtaceae), Laurus nobilis (Lauraceae), Mentha piperita (Lamiaceae), Myrtus communis (Myrtaceae), Fruit of Elaeagnus angustifolia (Elaeagnaceae), Terminalia chebula (Combretaceae), Resin of Boswellia sacra (Burseraceae), Root of Panax ginseng (Araliaceae), seed of Nigella sativa. (Ranunculaceae), gel of Aloe vera (Asphodelaceae), floret of Rosa damascene. (Rosaceae), and gall of Quercus infectoria (Fagaceae).

All plants were identified botanically and a voucher specimen was deposited in the herbarium of the Herbal Medicine Research Center Faculty of Pharmacy, Kerman university of Medical Sciences, Kerman, Iran.

\section{Plant Extraction}

Air dried plant materials were powdered, passed through sieve (Mesh 35) and were extracted separately by methanol, ethanol and water for 72 hours using warm maceration method. Each extract was concentrated under vacuum and dried at less than $40^{\circ} \mathrm{C}$ in the oven. The extracts were kept at $-20^{\circ} \mathrm{C}$ in dark bottles until use. The methanol extract which exhibited the greatest antibacterial activity was fractionated by column chromatography (CC) method with different ratio of hexane, ethyl acetate and methanol as explained previously. The fractions were collected, concentrated under vacuum and stored at $-20^{\circ} \mathrm{C}$ until experiments. ${ }^{16}$

\section{Bacterial Strains Used in this Study}

Five strains of $P$. aeruginosa including PAO1 (MH873, MS.PS 50/30, PAO wild and PDO 300 (MUCA2e) and ATCC 27853 were used in initial screening tests (14). Also, the E. coli strain ATCC 25922 and 20 clinical isolates of $P$. aeruginosa and E. coli were included in this study. These isolates were selected from a collection of isolates in our previous studies. All the 20 clinical isolates were MDR and with high MIC against CAZ (MIC: ranging 64-4096 $\mu \mathrm{g} / \mathrm{mL}$ ) (Table 1).

\section{Antibacterial Screening QIG Extracts and Separated Fractions}

The MIC of the extract and antibacterial agents was determined using agar dilution. ${ }^{17}$ Briefly, final concentrations of 250,500, 1000 and $2000 \mu \mathrm{g} / \mathrm{mL}$ of the extracts were added to autoclaved Muller-Hinton agar (HiMedia, India) at about $55^{\circ} \mathrm{C}$. The medium was poured into $10-\mathrm{cm}$ plates and incubated overnight at $35^{\circ} \mathrm{C}$ for dryness and detection of any possible contamination. Suspensions of standard bacterial strains were prepared and $0.5 \mathrm{McF}$ arland Standards of each bacterial suspension was diluted 1:100 and spot inoculated on the agar medium using a hand inoculator (Mast Chemical Company England). The MIC endpoint was considered as the lowest concentration of plant extract or antibacterial agents that completely inhibited the growth of the test organism under suitable incubation conditions. ${ }^{17}$

\section{Selection of the Plant Extract for Synergistic Activity with Ceftazidime \\ After determination of the MIC, ethyl acetate-methanol (7:3) extract fraction of $Q$. infectoria plant which exhibited the least MIC $(1000 \mu \mathrm{g} / \mathrm{mL})$ against all standard bacterial strains was selected for further studies (Table 1).}

Checker Board assay for Determination of Interaction 
Table 1. Minimum Inhibitory Concentration of Ceftazidime Against 20 Multidrug Resistant Clinical Isolates of P. aeruginosa and E. coli.

\begin{tabular}{|c|c|c|}
\hline \multirow{2}{*}{ Ceftazidime MIC of $\mu \mathrm{g} / \mathrm{mL}$} & \multicolumn{2}{|c|}{$\begin{array}{c}\text { Number of clinical isolates with } \\
\text { indicated MIC }\end{array}$} \\
\hline & P. aeruginosa & E. coli \\
\hline 64 & 1 & 1 \\
\hline 128 & - & 3 \\
\hline 256 & 6 & 3 \\
\hline 512 & 8 & 8 \\
\hline$\geq 1024$ & 5 & 5 \\
\hline
\end{tabular}

between CAZ and Q. infectoria on Multi Drug Resistant $P$. aeruginosa and E. coli Isolates

In the broth micro dilution method, the Q. infectoria extract was not completely dissolved in the broth; therefore, the antimicrobial effects were tested by the agar dilution method. The assay was carried out using agar dilution on Muller-Hinton agars containing various concentrations of CAZ and ethyl acetate-methanol (7:3) extract fraction of $Q$. infectoria. The concentration for CAZ was selected based on the MIC determined for standard bacterial strains (the MIC for all strains was 1 $\mu \mathrm{g} / \mathrm{mL}$ except for strain MS.PS 50/30 which was $4 \mu \mathrm{g} / \mathrm{mL}$ ). The Q. infectoria extract concentrations were serially diluted and ranged from 2000 to $62.5 \mu \mathrm{g} / \mathrm{mL}$ and CAZ serial dilutions ranged from 32 to $1 \mu \mathrm{g} / \mathrm{mL}$ (Table 2). Stock solution for preparing final concentration of crude extract two fold above MIC (for determination of antagonistic reaction) and 4 times below MIC (64, 125, 250 and 500 $\mu \mathrm{g} / \mathrm{mL}$ ) in $25-\mathrm{mL}$ Muller-Hinton agar were prepared. The stock solution for CAZ with final concentration of 4, 8, 16 and $32 \mu \mathrm{g} / \mathrm{mL}$ was also prepared and different concentrations of extract and CAZ were mixed with agar at $55^{\circ} \mathrm{C}$, the medium was poured into plates and the plates were stored as mentioned for MIC determination and were spot inoculated with standard and clinical bacterial strains. The fractional inhibitory concentration (FIC) was derived from the lowest concentration of the combination of CAZ with the extract allowing no observable growth of the test bacteria on the plates. The interaction between the extract with CAZ was evaluated by the FIC concentration calculated as the MIC of the extract in combination with antibacterial agent, divided by the MIC of the agent alone. The results were interpreted based on fraction inhibitory index (FICI) using the following formula:

$\sum$ FICI=FIC (crude extract: A) + FIC (ceftazidime: B)

Where FIC $(\mathrm{A})=\frac{M I C(A) \text { in combination }}{M I C(A) \text { alone }}+$ FIC $(B)=\frac{\text { FIC }(B) \text { in combination }}{M I C(B) \text { alone }}$

Synergistic activity between the extract and crude drug extract or fractionated plant extract was interpreted as synergistic activity when FICI was $\leq 0.5$, as indifference when between $1-4$, and as antagonistic when $>4$ (6).

\section{Measuring Ferric Reducing Antioxidant Power}

The reducing power of QIG and ethyl acetate-methanol extract fraction was tested by the ferric reducing antioxidant power (FRAP) method. ${ }^{18}$ At low $\mathrm{pH}$, some antioxidant components are able to reduce ferric tripyridyl triazine (Fe III-TPTZ) complex to an intense blue-colored ferrous (Fe II) form. This complex can be monitored by measuring the absorbance at $593 \mathrm{~nm}$ and the blue color intensity is proportional to the antioxidant capacity. Briefly, $5 \mu \mathrm{L}$ of different concentrations of QIG (ethyl acetate-methanol fraction) extract $(125 \mu \mathrm{g} / \mathrm{mL}$ to $2000 \mu \mathrm{g} / \mathrm{mL}$ ) and $70 \mu \mathrm{L}$ of FRAP reagent were mixed. Distilled water was used as a blank, the mixture was incubated at $37^{\circ} \mathrm{C}$ for 5 minutes, and absorbance was read at $593 \mathrm{~nm}$. The standard curve was plotted and the FRAP level of unknown samples was calculated by means of different concentrations (100 to $1000 \mu \mathrm{M})$ of $\mathrm{FeSO}_{4} 7 \mathrm{H} 2 \mathrm{O}$.

\section{Results}

\section{Antibacterial Activity of Plant Extracts}

In general, the aqueous extracts of all tested plants had no or very low antibacterial activity (MIC $\geq 2000 \mu \mathrm{g} / \mathrm{mL}$ ). Methanol and ethanol extract of Quercus infectoria and Myrtus communis showed an inhibitory activity against standard bacterial strains at concentrations of 1000 and $2000 \mu \mathrm{g} / \mathrm{mL}$, respectively. The methanol and ethanol extracts of Q. infectoria reduced the growth of all tested bacterial strains at a concentration of $500 \mathrm{mg} / \mathrm{mL}$ but completely inhibited the growth of all bacterial strains at a concentration of $1000 \mu \mathrm{g} / \mathrm{mL}$. The percent yield of the extracts was generally higher in methanol or ethanol in comparison to water extracts and per cent yield of Q. infectoria extract was $22.5 \%$ (dry extract weight/dry plant material weight $\mathrm{x}$ 100). The antibacterial activity of different concentrations of hexane methanol fractions

Table 2. Synergistic Activity of Ethyl Acetate-Methanol Fraction 7:3 of QIG Extract Shown as the Reducing Effect in MIC Against Combination of Various Concentration of Extract with Ceftazidime on 20 Multidrug Resistant Clinical Isolates of P. aeruginosa and E. coli

\begin{tabular}{|c|c|c|c|c|}
\hline \multirow{2}{*}{$\begin{array}{l}\text { Methanol or fractionated Constitute of the QIG } \\
\text { extract alone* or in combination with CAZ }\end{array}$} & \multicolumn{2}{|c|}{$\begin{array}{c}\mathrm{MIC} \mu \mathrm{g} / \mathrm{ml} \\
\mathrm{QIG} / \mathrm{CAZ}\end{array}$} & \multicolumn{2}{|c|}{ Fold decrease in MIC } \\
\hline & P. aeruginosa & E. coli & P. aeruginosa & E. coli \\
\hline Methanol extract ${ }^{*}$ & $1000 /$ nd & $1000 /$ nd & nd & nd \\
\hline Ethyl acetate- methanol $(7: 3)$ & $250 / 4$ & $250 / 16$ & $4 / 16-256$ & 4/ $16-64$ \\
\hline Ethyl acetate- methanol $(4: 1)^{*}$ & $250 / 16$ & $500 / 32$ & 4/ 4-64 & $2 / 2-32$ \\
\hline Ethyl acetate- methanol $(1: 1)^{*}$ & $500 / 16$ & $1000 / 32$ & $2 / 4-64$ & $0 / 2-32$ \\
\hline Ethyl acetate- methanol $(3: 2)^{*}$ & $250 / 16$ & $500 / 32$ & $4 / 4-64$ & $2 / 2-32$ \\
\hline
\end{tabular}

nd: Not determined. 
had lower activity than the methanol extract alone (MIC $\geq 2000 \mu \mathrm{g} / \mathrm{mL}$ ), while the fractionation constitutes of methanol ethyl acetate- methanol (7:3) had a completely similar antibacterial activity as the methanol extract before fractionation (Table 2).

\section{Synergistic Activity of QIG Extracts in Combination with CAZ on Standard and Clinical Strains of P. aeruginosa and E. coli}

In the agar dilution method, regardless of the high MIC to CAZ (Table 1), ethyl acetate-methanol fraction of $Q$. infectoria extract was able to reduce the MIC of CAZ in clinical isolates of $P$. aeruginosa to $4 \mu \mathrm{g} / \mathrm{mL}$, and $E$. coli to $16 \mu \mathrm{g} / \mathrm{mL}$, showing a high synergistic activity. Moreover, the MIC to the extract was also reduced four folds in the presence of CAZ (Table 2). The effect of the extract was slightly higher on $P$. aeruginosa compared to E. coli. and the inhibitory concentration index (FICI) for methanol extract ranged from 0.25 to 0.5 for $E$. coli and 0.25 for $P$. aeruginosa and both showed a strong synergistic activity especially reducing the MIC to CAZ. For all the standard strains of P. aeruginosa and, E. coli ATCC 25922 which were all sensitive to $\mathrm{CAZ}$, the combination effect reduced the MIC to QIG but not the CAZ and FICI ranged from 1.25 to 1.5 which was interpreted as an indifference effect. The QIG methanol extract at sub MIC concentration results in morphology change of the bacteria and the cells were rounded up (results not shown). The effects of various fractions of ethyl acetate-methanol fraction of the extract are shown in Table 2.

\section{Assessment of Antioxidant Properties}

The antioxidant properties of QIG ethyl acetate-methanol extract fraction was evaluated using FRAP method assay. The antioxidant activities of extract at different concentrations of $125,250,500,1000$ and $2000 \mu \mathrm{g} / \mathrm{mL}$ were respectively $340,560,800,860$, and $900 \mu \mathrm{M}$.

\section{Discussion}

Natural products from plants were used from ancient times for treatment of various disorders. Most of active plant extracts were identified when they were used as food additives and when the patient recovered from the disease; thus, the plants were used over and over by patients with similar symptoms. It is worthy to test plant extracts as a candidate for development of novel drugs to treat various bacterial infections. Generally, plant extracts are more active against gram positive bacteria compared to gram negative bacteria. ${ }^{5,9,12,19}$ This could be due to the structure of the outer membrane of gram-negative bacteria which makes them less permeable to the action of different materials passing this barrier. ${ }^{12}$ Additionally, the periplasmic space contains enzymes that can degrade the incoming molecules. $P$. aeruginosa has an impermeable outer membrane and medicinal plants usually need a high concentration to inhibit the growth of this bacterium. In the present study, methanol extracts were more active than water extracts; this is not surprising since alcohols are better solvents than water and due to their polar nature, they can dissolve both polar and nonpolar materials. ${ }^{5}$ Antibacterial and anti-quorum sensing activity of $Q$. infectoria has been studied by many investigators with an emphasis on the effect of this extract on P. aeruginosa. ${ }^{15}$, 19-22 This study showed that this extract was more active against $P$. aeruginosa isolates (reducing the MIC to $4 \mu \mathrm{g}$ / $\mathrm{mL}$ ) in comparison with E. coli (MIC was reduced to 164 $\mu \mathrm{g} / \mathrm{mL}$ ). The interesting and off-standing point of this study is that the combination of $Q$. infectoria and CAZ reverted the resistance strains to susceptible in case of $P$. aeruginosa and to intermediate category in case of $E$. coli despite their high MIC $(\geq 1024 \mu \mathrm{g} / \mathrm{mL})$ against CAZ. This is in accordance with the results reported for combination of $Q$. infectoria with vancomycin against two methicillinresistant Staphylococcus aureus strains. ${ }^{6}$ Many other reports showed the reduced MIC of antibacterial agents in the presence of plant extracts or even the loss of MDR phenotype. ${ }^{5,9,10,21}$ The mechanism by which plant extracts inhibit bacterial growth and further the synergistic activity between plant extracts and antibacterial agents are not fully explained. Possible mechanisms by which bacteria are inhibited from growth or killed by natural products are cell lysis due to the disintegration of cytoplasmic membrane, destabilization effect on proton motive force, coagulation of cell content, electron flow, inhibition of drug efflux pump, and alternative mechanism of action of the extract with the antibacterial agents. ${ }^{12,22,23}$ The result of this study showed an outstanding synergistic activity of Q. infectoria extract on reducing the MIC to CAZ. The plant extract may facilitate the penetration of CAZ into bacterial cell or otherwise inhibit the efflux pump activity. This work could be a starting point for more sophisticated research to determine the active part of plant extract, and the mechanism behind the combination effect of extract with CAZ. QIG extract has been reported to possess potent free radical scavenging and antioxidant activity. ${ }^{1824,25}$ In FRAP assay, the antioxidant potential of QIG ethyl acetate-methanol fraction was estimated from its ability to reduce TPTZ-Fe (III) complex to TPTZFe (II). The results obtained from this assay exhibited potent antioxidant activity of this extract. Working on combination of QIG and CAZ may lead to finding a new potent antibacterial agent against multidrug resistance organisms such as $P$. aeruginosa.

\section{Authors' Contribution}

SM designed the analysis. SM, AS, EI and MR conducted the experiment and collected the data. SM performed the analysis. FSH has given pharmaceutical advice. SM wrote the paper All read and confirmed the final version of manuscript for publication.

\section{Conflict of Interest Disclosures}

There is no conflict of interest. This manuscript had been read and approved by all authors; all the authors met the criteria for 
authorship. All the authors agree with an honest work presented in this study.

\section{Ethical Statement}

This study protocol was approved by the ethics committee of Kerman university of medical science (Ethical code: IR.kmu. REC.1394.459).

\section{Funding}

This research was supported by Kerman University of Medical Sciences (Grant number94-462).

\section{Acknowledgement}

We would like to thank Dr. Hoseini Naveh for his contribution by giving many helpful insights.

\section{References}

1. Rizvi ZA, Abbas S, Khalid S, Ali M. A comparison of antimicrobial resistance of XDR and MDR clinical isolates of E. coli, Klebsiella spp. \& Pseudomonas spp. against amikacin \& imipenem. J Rawalpindi Med Coll. 2019;23(Suppl 2):86-9.

2. Banin E, Hughes D, Kuipers OP. Bacterial pathogens, antibiotics and antibiotic resistance. FEMS Microbiol Rev. 2017;41(3):450-2. doi: 10.1093/femsre/fux016.

3. Cepas V, López Y, Muñoz E, Rolo D, Ardanuy C, Martí $\mathrm{S}$, et al. Relationship between biofilm formation and antimicrobial resistance in gram-negative bacteria. Microb Drug Resist. 2019;25(1):72-9. doi: 10.1089/mdr.2018.0027.

4. Karaiskos I, Antoniadou A, Giamarellou H. Combination therapy for extensively-drug resistant gram-negative bacteria. Expert Rev Anti Infect Ther. 2017;15(12):1123-40. doi: 10.1080/14787210.2017.1410434.

5. El-Zawahry YA, Reda FM, Azazy WM. Synergistic effect of combination treatment by certain plant extracts and some antibiotics on the resistance of pathogenic bacteria to some common antibiotics. Life Sci J. 2013;10(4):3477-89.

6. Farooqui A, Khan A, Borghetto I, Kazmi SU, Rubino S, Paglietti B. Synergistic antimicrobial activity of Camellia sinensis and Juglans regia against multidrug-resistant bacteria. PLoS One. 2015;10(2):e0118431. doi: 10.1371/ journal.pone.0118431.

7. Rai M, Paralikar P, Jogee P, Agarkar G, Ingle AP, Derita $\mathrm{M}$, et al. Synergistic antimicrobial potential of essential oils in combination with nanoparticles: emerging trends and future perspectives. Int J Pharm. 2017;519(1-2):67-78. doi: 10.1016/j.ijpharm.2017.01.013.

8. Adonizio A, Kong KF, Mathee K. Inhibition of quorum sensing-controlled virulence factor production in Pseudomonas aeruginosa by South Florida plant extracts. Antimicrob Agents Chemother. 2008;52(1):198-203. doi: 10.1128/aac.00612-07.

9. Limsuwan S, Subhadhirasakul S, Voravuthikunchai SP. Medicinal plants with significant activity against important pathogenic bacteria. Pharm Biol. 2009;47(8):683-9. doi: 10.1080/13880200902930415.

10. Elbashiti TA, Elmanama AA, Masad AA. The antibacterial and synergistic effects of some Palestinian plant extracts on Escherichia coli and Staphylococcus aureus. Funct Plant Sci Biotechnol. 2011;5:57-62.

11. Rabadia A, Kamat S, Kamat D. Study of synergistic action of cefotaxime and Terminalia chebula on Acinetobacter baumannii using checkerboard assay. Int J Pharm Pharm
Sci. 2013;5(3):830-2.

12. Tegos G, Stermitz FR, Lomovskaya O, Lewis K. Multidrug pump inhibitors uncover remarkable activity of plant antimicrobials. Antimicrob Agents Chemother. 2002;46(10):3133-41. doi: 10.1128/aac.46.10.31333141.2002 .

13. Jamshidzadeh A, Shokri Y, Ahmadi N, Mohamadi N, Sharififar F. Quercus infectoria and Terminalia chebula decrease melanin content and tyrosinase activity in B16/ F10 cell lines. J Pharm Pharmacogn Res. 2017;5(5):270-7.

14. Mansouri S, Safa A, Gholamhoseinian Najar S, Gholamhoseinian Najar A. Inhibitory activity of Iranian plant extracts on growth and biofilm formation by Pseudomonas aeruginosa. Malays J Microbiol. 2013;9(2):176-83. doi: 10.21161/mjm.47612.

15. Mohabi S, Kalantar-Neyestanaki D, Mansouri S. Inhibition of quorum sensing-controlled virulence factor production in Pseudomonas aeruginosa by Quercus infectoria gall extracts. Iran J Microbiol. 2017;9(1):26-32.

16. Sharififar F, Dehghan-Nudeh G, Raeiat Z, Amirheidari B, Moshrefi M, Purhemati A. Tyrosinase inhibitory activity of major fractions of Quercus infectoria galls. Pharmacogn Commun. 2013;3(1):21-6. doi: 10.5530/pc.2013.1.6.

17. Balouiri M, Sadiki M, Ibnsouda SK. Methods for in vitro evaluating antimicrobial activity: a review. J Pharm Anal. 2016;6(2):71-9. doi: 10.1016/j.jpha.2015.11.005.

18. Mandegary A, Sharififar F, Sheibani V, Nasehi N, Asadi A, Mirtadzadini M, et al. An standardized extract from textured soy protein (Glycine max L.) has ameliorating effect on memory deficit and learning insufficiency in scopolamine-induced amnesia. Basic Clin Neurosci. 2021;36(1):60-90. doi: 10.32598/bcn.2021.2446.1.

19. Darogha SN. Antibacterial activity of Quercus infectoria extracts against bacterial isolated from wound infection. Kirkuk Univ J Sci Stud. 2009;4(1):20-30.

20. Basri DF, Fan SH. The potential of aqueous and acetone extracts of galls of Quercus infectoria as antibacterial agents. Indian J Pharmacol. 2005;37(1):26-9. doi: 10.4103/02537613.13851.

21. Tasdelen Fisgin N, Tanriverdi Cayci Y, Coban AY, Ozatli D, Tanyel E, Durupinar B, et al. Antimicrobial activity of plant extract Ankaferd Blood Stopper. Fitoterapia. 2009;80(1):48-50. doi: 10.1016/j.fitote.2008.09.006.

22. Akinyele TA, Igbinosa EO, Akinpelu DA, Okoh AI. In vitro assessment of the synergism between extracts of Cocos nucifera husk and some standard antibiotics. Asian Pac J Trop Biomed. 2017;7(4):306-13. doi: 10.1016/j. apjtb.2016.12.022.

23. Jayaraman $\mathrm{P}$, Sakharkar MK, Lim CS, Tang TH, Sakharkar KR. Activity and interactions of antibiotic and phytochemical combinations against Pseudomonas aeruginosa in vitro. Int J Biol Sci. 2010;6(6):556-68. doi: 10.7150/ijbs.6.556.

24. Khazaeli P, Goldoozian R, Sharififar F. An evaluation of extracts of five traditional medicinal plants from Iran on the inhibition of mushroom tyrosinase activity and scavenging of free radicals. Int J Cosmet Sci. 2009;31(5):375-81. doi: 10.1111/j.1468-2494.2009.00503.x.

25. Wan-Ibrahim WI, Sidik K, Kuppusamy UR. A high antioxidant level in edible plants is associated with genotoxic properties. Food Chem. 2010;122(4):1139-44. doi: 10.1016/j.foodchem.2010.03.101 